\title{
Erratum to: Abuse and dependence liability analysis of methylphenidate in the spontaneously hypertensive rat model of attention-deficit/hyperactivity disorder (ADHD): what have we learned?
}

Ike dela Peña $\cdot$ Bung-Nyun Kim $\cdot$ Doug Hyun Han •

Yeni Kim $\cdot$ Jae Hoon Cheong

Published online: 30 April 2013

(c) The Pharmaceutical Society of Korea 2013

Erratum to: Arch. Pharm. Res.

DOI 10.1007/s12272-013-0037-2

publication. Please find all the authors and their affiliations in this erratum.

Unfortunately, not all the authors who contributed to this article were included in the author group in the original

The online version of the original article can be found under doi:10.1007/s12272-013-0037-2.

I. dela Peña $\cdot$ J. H. Cheong ( ( )

Department of Pharmacy, Sahmyook University,

26-21 Kongreung-2-dong, Hwarangro-815, Nowon-gu,

Seoul 139-742, Korea

e-mail: cheongjh@syu.ac.kr

B.-N. Kim

Division of Child \& Adolescent Psychiatry, Department of Psychiatry, College of Medicine, Seoul National University, Seoul 151-742, Korea

D. H. Han

Department of Psychiatry, College of Medicine, Chung-Ang University, Seoul 156-756, Korea

Y. Kim

Department of Child \& Adolescent Psychiatry, Seoul National Hospital, Seoul 143-711, Korea 